\title{
Altered blood proteome in girls with high urine concentrations of bisphenol a, genistein, mono-ethyl hexylphthalate and mono-benzyl phthalate
}

\begin{abstract}
Children exposed to endocrine disruptors are hypothesized to be susceptible for cancer development later in life. Identifying functional biomarkers of specific exposures may indicate predisposition for this disease. The objectives of this study were to identify protein biomarkers of 1) effect and 2) susceptibility for cancer from the blood of girls exposed to select environmental chemicals. In prepubertal girls, urine concentrations of bisphenol A (BPA), genistein, mono-ethyl hexylphthalate (MEHP) and monobenzyl phthalate (MBzP) were used to identify girls in the top quintile of exposure for each of these environmental chemicals, and age-matched prepubertal girls with urine analyte concentrations below the median. Blood samples of these girls were depleted of the seven most abundant proteins using human-specific affinity spin columns. Using isobaric Tandem Mass Tags and quantitative mass spectrometry (TMT-MS), 51, 34, 57 and 47 differentially expressed proteins were identified from the blood of prepubertal girls with high urine concentrations of BPA, genistein, MEHP and MBzP, respectively, compared to controls. The data demonstrates the potential of proteomic technology to not only provide biomarkers of effect from aminimally invasive source of biological material, blood, but to identify protein molecules that are intimately involved in the pathobiology of cancer. The differentially regulated cancer associated proteins in girls with high concentrations of BPA and genistein are consistent with reported roles of BPA in carcinogenesis and of genistein in mammary cancer prevention, respectively.
\end{abstract}

Keywords: girls, blood, biomarkers, proteomics, toxicology, cancer
Volume 2 Issue 2 - 2015

\author{
Jun Wang,' Angela Betancourt,' Sarah \\ Jenkins, ' Frank Biro, ${ }^{2}$ Susan M Pinney, ${ }^{3}$ \\ Dongquan Chen, ${ }^{4,5}$ Jose Russo, ${ }^{6}$ Coral A \\ Lamartiniere ${ }^{1,5}$ \\ 'Department of Pharmacology and Toxicology, University of \\ Alabama at Birmingham, USA \\ ${ }^{2}$ Division of Adolescent Medicine, Children's Hospital Medical \\ Center, USA \\ ${ }^{3}$ Department of Environmental Health, University of Cincinnati \\ College of Medicine, USA \\ ${ }^{4}$ Division of Preventive Medicine, UAB \\ ${ }^{5} \mathrm{UAB}$ Comprehensive Cancer Center, University of Alabama at \\ Birmingham, USA \\ ${ }^{6}$ The Irma Russo Breast Cancer Research Laboratory, Fox \\ Chase Cancer Center-Temple University Health System, USA
}

Correspondence: Coral A Lamartiniere, Department of Pharmacology and Toxicology, University of Alabama at Birmingham, 1670 University Boulevard,VH 24I, Alabama 35294 USA, Tel 2057900573, Fax 2059348240, Email Coral@uab.edu

Received: December 30,2014 | Published: March 10,2015
Abbreviations: AIN, american institute of nutrition; BBP, butyl benzyl phthalate; BPA, bisphenol a; BW, body weight; DEHP, di-(2-ethylhexyl)phthalate; DLC1, deleted in liver cancer 1; DNM3B, DNA (cytosine-5)-methyltransferase 3b; ECE-1, endotheliumconverting enzyme;EIF3, eukaryotic initiation factor 3; FDR, false discovery rate; KLF10, krueppel-like factor 10; IGFBP-3, insulin growth factor binding protein 3; Mbzp, mono-benzyl phthalate; MEHP, mono-ethyl hexylphthalate; MKK4, mitogen-activated kinase kinase 4; MS, mass spectrometry; Mudpit, multidimensional protein identification technology; NMU, n-nitroso-n methylurea; PANTHER, protein analysis through evolutionary relationships system; PRDM5, pr domain zinc finger 5; PQD, pulsed q dissociation; RAD54B, rad54 homolog b; RB1, retinoblastoma-associated protein; SAM, significance analysis of microarray; TMT, tandem mass tags; TRPC5, transient receptor potential channel 5

\section{Introduction}

Natural and man-made chemicals may act as endocrine disruptors, interacting with hormone receptors, influencing synthesis and metabolism of hormones and transcription factors, and affecting the hypothalamic-pituitary-gonadal axis ${ }^{1}$ One example is BPA, which is used in the manufacture of children's polycarbonate milk bottles, toys, lining of food and soft drink cans, cash register receipts and many plastic products. BPA can leach from these containers and products and be ingested. ${ }^{2}$ Exposure of the American population to BPA has been detected in $92.6 \%$ sampled urine, with concentrations of 0.4 to $149 \mathrm{ng} /$ $\mathrm{mL} .{ }^{3,4}$ Epidemiological studies have shown an association between BPA exposure and cardiovascular disease,,${ }^{5}$ obesity, ${ }^{6}$ diabetes, ${ }^{7}$ and cancer. ${ }^{8-10}$ Durando et al., ${ }^{11}$ have shown that prenatal exposure to BPA coupled to a sub-carcinogenic dose of N-nitroso-N methylurea (NMU) resulted in an increased percentage of pre neoplastic and neoplastic lesions in the rat mammary gland. Murray et al., ${ }^{12}$ showed that fetal exposure of rats to BPA induced mammary gland ductal hyperplasia and carcinoma in situ. Jenkins et al., ${ }^{13}$ reported that prepubertal exposure to BPA increased susceptibility for chemicallyinduced mammary cancer in rats.

Phthalates are used in the manufacture of polyvinylchloride water pipes, vinyl and carpet tiles, artificial leather, detergents, lubricating oils, certain adhesives, plastic food wrap, children's toys and found in cosmetics and shampoos. ${ }^{14}$ In the United States, it has been estimated that the levels of phthalates in foods can vary between $50-500 \mathrm{mg}$ / $\mathrm{kg}{ }^{15,16}$ The best estimate of exposure to the general public is $2 \mu \mathrm{g} /$ $\mathrm{kg}$ body weight (BW)/day from food in adults, with exposures to infants and children up to 3 -fold higher. ${ }^{17}$ A significant delay in the age at vaginal opening (approximately 2days) in rat offspring from dams exposed to $15 \mathrm{mg}$ di-(2-ethylhexyl)phthalate (DEHP)/kg bw/ day during pregnancy and during lactation has been reported..$^{18}$ are some of the adverse effects seen in adult female rats exposed to high doses of DEHP. ${ }^{19}$ Using a recombinant yeast screen for estrogenic activity, butyl benzyl phthalate (BBP) was found to be the most potent phthalate, although approximately 1x106 less than 17betaestradiol. ${ }^{20}$ Phthalates that were estrogenic in the yeast screen are also mitogenicin human breast cancer cells. ${ }^{21} \mathrm{~A}$ study of girls with early the larche suggests a possible association between plasticizers with known estrogenic and anti androgenic activity and the cause of premature breast development in the human female population. ${ }^{22}$ 
Certain phthalates have been reported to enhance liver and skin carcinogenesis in rodents, and to act as weak estrogens toward human breast cancer cells. ${ }^{22-24}$

Genistein is an isoflavone component of soy. Soy-based diets are high in phytochemicals and quantitative results indicate that phytoestrogens are normal constituents of human urine from participants consuming large amounts of soy products (tofu, soy flour, soy milk, tempeh, etc). ${ }^{25}$ Asian women, consuming a diet high in soy products, have a low incidence of breast cancer. ${ }^{26,27}$ Yet, Asians who immigrate to the United States and adopt a western diet lose this protection. An epidemiology report showed the importance of the adolescent period in humans, demonstrating a significant reduction of breast cancer risk in 13-15year old adolescent girls consuming soy. ${ }^{28}$ Genistein has been reported to be an anti-oxidant, to inhibit protein tyrosine kinases, topoisomerase II and angiogenesis, and to induce cell differentiation. ${ }^{29}$

Over the last decade, an emphasis has been placed on investigating the role of environmental chemicals on puberty and predisposition for breast cancer. Importantly, the mammary gland in humans is, to a great extent postnatally developed and subject to many endogenous and exogenous stimuli. With this comes the need to implement new technology to measure biomarkers of effect and susceptibility for cancer in order to determine if early chemical exposure can predispose to breast cancer. This report breaks from the accepted dogma of using genomic markers and moving to a more practical aspect of biomarkers that actually reflect function, proteins. Proteins, as enzymes, cofactors and regulators, actually carryout the enzymatic actions and support many metabolic processes. Although there are a plethora of papers that examine gene expression, the latter may not always translate into protein action. Working with collaborative teams of basic scientists and epidemiologists from several institutions, we have teamed up to optimized our resources (human recruitments, animal models and technology) to investigate protein biomarkers of effect from prepubertal girls from whom blood and urine were collected. From the urine of these girls, the concentration of chemical analytes was available. ${ }^{30}$ From our animal studies, we determined that two of the measured chemicals, BPA and genistein, could alter predisposition for mammary cancer in animal models. ${ }^{31}$ Two other chemicals, DEHP and $\mathrm{BBP}$, were also of interest to the group because of their high metabolite concentrations in the urine of these young girls. Using recently optimized methods of rat blood protein enrichment and tagging, and mass spectrometry analysis for identification of proteins, ${ }^{32}$ we report for the first time blood protein biomarkers of effect and susceptibility from prepubertal girls with high concentrations of BPA, genistein, MEHP and MBzP (the latter two, metabolites of DEHP and BBP, respectively).

\section{Materials and methods}

\section{Chemicals}

Rabbit polyclonal antibodies to endothelium-converting enzyme (ECE-1; cat\# sc-25841) and deleted in liver cancer 1 (DLC-1; cat\# sc32931) were purchased from Santa Cruz Biotechnology, Inc. (Dallas, TX). Rabbit monoclonal antibody to eukaryotic initiation factor 3a (EIF-3a; cat\# 3411) was purchased from Cell Signaling Technology (Danvers, Massachusetts). The secondary antibody (Goat antiRabbit IgG HRP Affinity Purified PAb) was purchased from R\&D Systems, Inc. (Minneapolis, MN) and Chemiluminescent Substrate from Thermo Fisher Scientific Inc. (Rockford, IL). SepproR IgY-H7 human-specific spin columns and BPA were purchased from Sigma
Chemical Co., St. Louis MO, and TMT label reagent from Thermo Scientific, Lafayette, CO. Genistein was provided by DSM Nutritional Products (Basel, Switzerland).

\section{Human blood amples}

This Genes, Environment, and Health Initiative study utilized blood collected from girls recruited via an epidemiology component of a Breast Cancer and Environment Research Center study. ${ }^{33}$ The latter was a longitudinal study of girls enrolled at 6-7years of age and followed through puberty. Enrollment occurred during 20042007 at Cincinnati Children's Hospital, which recruited in the greater Cincinnati, $\mathrm{OH}$ metropolitan area. Informed consent from parent or guardian was obtained with child assent; the study was approved by the Institutional Review Board at Cincinnati Children's Hospital Medical Center. Eligibility included age (six to seven years old), female, and no underlying endocrine medical conditions. BPA and genistein, and the metabolites, MEHP for DEHP, and MBzP for BBP were measured from urine samples of girls who were prepubertal at ages six and seven. Details of the procedures used for the measurement of these environmental chemical analytes were provided elsewhere. ${ }^{30}$ These measurements were used to separate the girls into quintiles of exposure for the above listed chemicals. Girls with urine creatininecorrected concentrations in the top quintile for a single chemical, but having urine creatinine-corrected concentrations below the median for all of the other chemicals, were selected for this study. Due to the limited number of blood samples available, samples were pooled as described below. Nine blood samples from girls in the top quintile of BPA exposure were pooled to create three high BPA (H-BPA) samples. Six blood samples from girls in the top quintile of MBzP exposure were pooled to create three H-MBzP samples. The three H-MEHP and three H-genistein samples were not pooled. Six blood samples from the girls with urine concentrations below the median for all chemicals studied were pooled to create three control samples.

\section{Serum sample preparation and at acquisition}

Three pooled serum samples for each group (controls, H-BPA, H-MEHP, H-MBzP, H-genistein) were depleted of the seven most abundant proteins via SepproR IgY-H7 human specific spin columns, concentrated via molecular weight cut off centrifugal filter devices, and protein concentrations of the concentrated samples were determined with the Bradford protein assay (Bio-Rad, Hercules, CA). One hundred micrograms of protein from each group were labeled with Amine-Reactive Tandem Mass Tag Reagents (TMT 6 Label Reagents; Thermo Scientific, Lafayette, CO) according to the protocol supplied by the manufacturer as previously described. ${ }^{32}$ Briefly, protein was solubilized in $100 \mathrm{mM}$ TEAB plus $0.1 \% \mathrm{SDS}$ and reduced with $9.5 \mathrm{mM}$ tris(2-carboxyethyl)phosphine for 1 hour at $55^{\circ} \mathrm{C}$ and then alkylated with $17 \mathrm{mM}$ iodoacetamide for $30 \mathrm{~min}$ in the dark, and digested with Trypsin Gold overnight at $37^{\circ} \mathrm{C}$ (Promega, Madison WI). Each sample was incubated with a specific TMT tag reconstituted in $41 \mu \mathrm{L}$ of $\mathrm{AcN}$ for 1 hour at room temperature. The reaction was quenched by adding $8 \mu \mathrm{L}$ of $5 \%$ hydroxylamine. Tagged samples were combined, and the labeled peptides were purified using a SCX Macrotrap (Cat.\#TR1/25109/55, Michrom Bioresources Inc. Auburn CA), and desalted using a Peptide Macrotrap (Cat.\#TR1/25109/52, Michrom Bioresources Inc.). Sample volumes were reduced in a Speed Vac to near dryness, and resuspended in $95 \% \mathrm{ddH} 2 \mathrm{O} / 5 \% \mathrm{ACN} / 0.1 \%$ formic acid to give a concentration of $2.5 \mu \mathrm{g} / \mu \mathrm{l}$.

Tagged samples were processed for analysis via an LTQ XL ion trap mass spectrometer equipped with a nano-electrospray source, 
and a Surveyor plus binary high-pressure liquid chromatography (HPLC) pump (Thermo Scientific, San Jose, CA) using a split flow configuration. Separations were carried out using a 14-fraction MudPIT approach, where the first column was a double-fritted 150micron IDx $7 \mathrm{~cm}$ SCX (Poly SULFOETHYL A 300 A, 5 micron, PolyLC), connected to a 150 micronx $13 \mathrm{~cm}$ pulled tip $\mathrm{C}-18$ column (Jupiter C-18 300 A, 5 micron, Phenomenex, Torrance, CA). The HPLC was set up with two mobile phases that included solvent A $(0.1 \%$ formic acid in $\mathrm{ddH} 2 \mathrm{O})$, and solvent $\mathrm{B}(0.1 \%$ formic acid in $85 \% \mathrm{ddH} 2 \mathrm{O} / 15 \% \mathrm{ACN}$ ), and was programmed as follows; $15 \mathrm{~min}$ @ 0\%B ( $2 \mu \mathrm{L} / \mathrm{min}$, load), 65min @ 0\%-50\%B ( 0.5nL/min, analyze) and 20min @ $0 \% \mathrm{~B}(2 \mu \mathrm{L} / \mathrm{min}$, equilibrate). This gradient was used for each step of the MudPIT analysis, in which the flow-through was first analyzed, followed by 13 additional fractions obtained by $35 \mu \mathrm{L}$ injections of the following concentrations of ammonium acetate dissolved in $\mathrm{ddH}_{2} \mathrm{O}: 25 \mathrm{mM}, 32.5 \mathrm{mM}, 40 \mathrm{mM}, 50 \mathrm{mM}, 75 \mathrm{mM}$, $100 \mathrm{mM}, 150 \mathrm{mM}, 200 \mathrm{mM}, 250 \mathrm{mM}, 300 \mathrm{mM}, 350 \mathrm{mM}, 400 \mathrm{mM}$, and $1 \mathrm{M}$. The LTQ XL was operated in data dependent triple play mode, with a survey scan range of $350-2000 \mathrm{~m} / \mathrm{z}$, followed by a zoom scan for charge state determination, and pulsed Q dissociation (PQD) scan for MS2, which were carried out with 2.0 Da isolation widths on the 3 top most intense ions. MS data were collected in profile mode for all scan types. Charge state screening and data dependent dynamic exclusion were enabled, with exclusion of non-assigned peptides, aminimum signal intensity of 2000 , a repeat count of 2 , and exclusion duration of $90 \mathrm{~s}$ for ions $+/-1.5 \mathrm{~m} / \mathrm{z}$ of the parent ion. The automatic gain control (AGC) settings were 3X104, 5x103, and 5x104 ions for survey, zoom, and PQD modes respectively. Scan times were set at 25,50 , and $250 \mathrm{~ms}$ for survey, zoom, and PQD modes respectively. For PQD, the activation time, activation Q, and normalized collision energy were set at $0.1 \mathrm{~ms}, 0.7$, and $35 \%$ respectively. The spray voltage was set at $1.9 \mathrm{kV}$, with a capillary temperature of $170^{\circ} \mathrm{C}$. All Mud PIT runs were carried out in duplicate.

\section{Data analysis}

The XCalibur RAW files were centroided and converted to MzXML and themgf files were then created using both ReAdW and MzXML2Search respectively (http://sourceforge.net/projects/ sashimi/). The data was searched using SEQUEST (v.27 rev12, dta files), set for two missed cleavages, a precursor mass window of 0.45 Da, tryptic enzyme, variable modification M @ 15.9949, and static modifications C@57.0293, K and N-term@229.1629. Searches were performed with a rat subset of the UniRef100 database, which included common contaminants such as digestion enzymes and human keratins. Identified peptides were filtered, grouped, and quantified using ProteoIQ (Premierbiosoft, Palo Alto, CA). Only peptides with charge state of $\geq 2+$, aminimum peptide length of 6 amino acids, and non-zero quantities for all six mass tags were accepted for analysis. ProteoIQ incorporates the two most common methods for statistical validation of large proteome datasets, false discovery rate (FDR), and protein probability. ${ }^{34,35}$ The FDR was set at $<1 \%$ cut-off, with a total group probability of $\geq 0.7$, with at least 2 peptides assigned per protein. Relative quantification was performed via spectral counting, and spectral count abundances were normalized between samples.

\section{Animals}

Cross-species and tissue validation of selected proteins were carried out from mammary tissue extracts of rats exposed prepubertally to BPA and genistein. Animal studies were conducted in accordance with the University of Alabama at Birmingham Guidelines for Animal Use and Care. Seven week old female Sprague-Dawley rats were purchased from Charles River Laboratories (Wilmington, MA). Animals were housed in a temperature controlled facility with a $12-\mathrm{h}$ light: dark cycle. These animals were bred with proven SpragueDawley studs in our facilities, provided phytoestrogen-free AIN-76A diet (Harlan Teklad, Madison, WS) and water via glass bottles, and housed in polypropylene cages (all polycarbonate/BPA free). On theday of birth, offspring were sexed, and litters were culled to 10 offspring per lactating dam. For BPA treatment, lactating dams were gavaged intragastrically with $250 \mu \mathrm{g} \mathrm{BPA} / \mathrm{kg} /$ day while controls received an equivalent volume of the vehicle sesame oil beginning on postnatal day 2 (PND2) and continuing through PND20. For genistein treatment, the lactating dams received $250 \mathrm{mg}$ genistein $/ \mathrm{kg}$ AIN-76A diet or AIN-76A diet only as controls from PND2 through PND20. In this manner, the offspring are exposed to genistein or BPA via the mother's milk. Offspring were weaned on PND21 and continued on AIN-76A diet only. At PND50, female offspring were killed in the estrous phase. The fourth abdominal mammary glands were rapidly dissected from live ketamine/xylazine anesthetized animals (tominimize proteolysis), snap-frozen in liquid nitrogen, and stored at $-80^{\circ} \mathrm{C}$ for later analysis.

\section{Western blot validation}

Western blot analyses were performed to validate changes in protein expressions detected by TMT-MS. Since human sera were limited, we carried out "cross-species" validation in mammary glands from 50day old rats exposed prepubertally to BPA and genistein (and controls). To determine the changes in protein expression, six mammary gland samples per treatment group were analyzed by Western blots. Each sample was derived from only one rat randomly selected from separate litters per treatment group. The same quantity of protein from each sample was separated by SDS-PAGE and transferred to a nitrocellulose membrane (Bio-Rad, Hercules, CA). The membranes were blocked and immuno blotted with appropriate antibodies including deleted in liver cancer 1 (DLC-1), endotheliumconverting enzyme (ECE-1) and eukaryotic initiation factor 3 (EIF3). Molecular weight ladders (Bio-Rad) were used to validate the proteins of interest. Nitrocellulose membranes were incubated with an appropriate secondary antibody conjugated to HRP (R\&D Systems, Inc) followed with a chemiluminescent substrate and exposed to X-ray radiography film. Quantitative analysis of protein expression was accomplished by scanning autoradiogram and densitometry (Image J, NIH).Western blot analyses were performed to validate changes in protein expressions detected by TMT-MS. Since human sera were limited, we carried out "cross-species" validation in mammary glands from 50day old rats exposed prepubertally to BPA and genistein (and controls). To determine the changes in protein expression, six mammary gland samples per treatment group were analyzed by Western blots. Each sample was derived from only one rat randomly selected from separate litters per treatment group. The same quantity of protein from each sample was separated by SDS-PAGE and transferred to a nitrocellulose membrane (Bio-Rad, Hercules, CA). The membranes were blocked and immunoblotted with appropriate antibodies including deleted in liver cancer 1 (DLC1), endothelium-converting enzyme (ECE-1) and eukaryotic initiation factor 3 (EIF3). Molecular weight ladders (Bio-Rad) were used to validate the proteins of interest. Nitrocellulose membranes were incubated with an appropriate secondary antibody conjugated to HRP (R\&D Systems, Inc) followed with a chemiluminescent substrate and exposed to X-ray radiography film. Quantitative analysis of protein expression was accomplished by scanning autoradiogram and densitometry (Image J, NIH). 


\section{Statistical analysis}

For urinary metabolite concentrations, each pooled sample group was compared against prepubertal control using a T-test for unequal variance to determine the statistical significance of the difference in means of the top quintile and control groups. P-values of $<0.05$ were considered statistically significant. For the proteomic data generated by TMT-MS, separate non-parametric statistical analyses were performed between each set of comparison groups. These nonparametric analyses include 1) the calculation of weight values by significance analysis of microarray ${ }^{34,35}$ (SAM; cut off $\left.\mid\right\} 0.8 \mid$ combined with 2) Wilcoxon (cut off of $\mathrm{p}<0.05$ ) which then were sorted according to the highest statistical relevance in each comparison. For SAM, whereby the weight value (W) is a statistically derived function that approaches significance as the distance between the means $(\mu 1-\mu 2)$ for each group increases, and the $\mathrm{SD}(\delta 1-\delta 2)$ decreases using the formula, $\mathrm{W}=(\mu 1-\mu 2) /(\delta 1+\delta 2)$. For protein abundance ratios determined with TMT-MS, we set a 2.0 fold change as the threshold for significance, determined empirically by analyzing the inner-quartile data from the control experiment indicated above using $\ln -\ln$ plots, where Pierson's correlation coefficient $(\mathrm{R})$ was 0.98 , and $>99 \%$ of the normalized intensities fell between $+/-1.5$ fold. In each case, any two of the three tests (SAM, Wilcoxon, or fold change) had to pass. Statistical analysis of Western blot analysis was performed by using one way analysis of variance $(A N O V A)$ to determine significance $(\mathrm{P}<0.05)$.

\section{Bioinformatics and systems biology analysis}

Those proteins found to have significantly changed in the high chemical exposed groups versus the control group were evaluated for biological significance, and for key biological functions to cancer related pathways. PANTHER (Protein Analysis through Evolutionary Relationships System) (http://www.pantherdb.org) was used for protein classification. Ingenuity Pathways Analysis (Ingenuity Systems, www.ingenuity.com) (IPA, Redwood City, CA) was used to identified the pathways from the IPA library of canonical pathways that were most significant in our dataset. Proteins from the dataset that met the criteria for differential expression and were associated with a canonical pathway in the Ingenuity Knowledge Base were considered for the analysis. Finally, proteins of interest were subjected to literature searches as to biological function and appropriateness as biomarkers of cancer susceptibility.

\section{Results and discussion}

The group of girls with high urinary concentrations of BPA, MEHP, and $\mathrm{MBzP}$ were significantly increased compared against respective controls (defined as urine samples below the median of the chemicals

\section{H-MBzP girls.}

Table 2 Differentially Regulated Proteins Identified by TMT-MS in Sera of Girls with High Urine Concentrations of BPA

\begin{tabular}{|c|c|c|c|c|c|}
\hline Protein IDa & Protein Name $^{b}$ & Group prob-ability & No. unique peptides & Fold change $(R x / C)^{c}$ & SAM $^{d}$ \\
\hline PI0323 & acrosin & 0.99 & 4 & +2.80 & 1.48 \\
\hline 075969 & A-kinase anchor & 0.94 & 2 & +2.52 & 2.38 \\
\hline Q0I484 & ankyrin-2 & 0.99 & 4 & +2.21 & 1.69 \\
\hline P46013 & antigen $\mathrm{Ki}-67$ & 0.95 & 4 & +3.65 & $\mathrm{I} .4 \mathrm{I}$ \\
\hline Q9P203 & BTB/POZ domain-containing 7 & 0.94 & 3 & +2.52 & 2.09 \\
\hline Q9UPV0 & centrosomal protein of I 64 & 0.98 & 2 & +3.04 & $\mathrm{I} .84$ \\
\hline B7ZMLI & chromodomain helicase DNA binding protein & 0.82 & 4 & +3.06 & 1.68 \\
\hline Q512W7 & cytochrome P450, family $24, \mathrm{AI}$ & 0.72 & 2 & -2.57 & 1.16 \\
\hline
\end{tabular}

Citation: Wang J, Betancourt A, Jenkins S, et al.Altered blood proteome in girls with high urine concentrations of bisphenol a, genistein, mono-ethyl hexylphthalate and mono-benzyl phthalate. MOJ Proteomics Bioinform. 20I5;2(2):44-57. DOI: I0.15406/mojpb.20I5.02.00040 analyzed) (Table 1). While girls with high urinary concentrations of genistein were increased 38 fold as compared to control urine samples, these did not reach statistical significance.

Table I Urinary Creatinine (Cr) Corrected Biomarker Concentrations (ng/g Cr)*

\begin{tabular}{lllll}
\hline Biomarker & Group & N & Mean \pm SD & P-Value \\
\hline BPA & Control & 6 & $1.1 \pm 0.4$ & \\
\multirow{3}{*}{ Genistein } & H-BPA & 9 & $17.5 \pm 11.2$ & $\mathrm{p}<0.01$ \\
& Control & 6 & $33.9 \pm 20.9$ & \\
MEPH & H-Genistein & 3 & $1286.4 \pm 860.3$ & $\mathrm{P}=0.13$ \\
& Control & 6 & $1.6 \pm 0.9$ & \\
MBzP & MEHP & 3 & $17.2 \pm 0.7$ & $\mathrm{P}<0.0001$ \\
& Control & 6 & $14.4 \pm 8.2$ & \\
& MBzP & 6 & $148.5 \pm 119.4$ & $\mathrm{P}<0.05$ \\
\hline
\end{tabular}

*Creatinine corrections were determined using creatinine measurements from the same urine specimens as for the blood biomarker measurements. A T-test for unequal variance was used to determine the statistical significance of the difference in means of the top quintile and control groups.

BPA, bisphenol a; MEHP, mono-ethyl hexyl-phthalate; MBzP, mono-benzyl phthalate

\section{Systems biology analysis}

Using TMT-MS technology, we identified 51, 34, 57 and 47 proteins to be differentially expressed from the blood of girls with $\mathrm{H}-\mathrm{BPA}, \mathrm{H}-$ genistein, H-MEHP and H-MBzP urine concentrations, respectively (Tables 2-5). Analysis of biological function via HER demonstrates that all four exposure groups had similar responses for metabolic process $(26-28 \%)$, cellular process (21$23 \%$ ), biological regulation (10-12\%) and developmental process (7had higher responses on localization (13\% and $14 \%$ responses, respectively) than the H-MEHP and H-MBzP groups (4\% and $8 \%$, respectively). In regard to cellular component organization or biogenesis, the $\mathrm{H}$-genistein group had only $5 \%$ response while $\mathrm{H}-\mathrm{BPA}$, MEHP and $\mathrm{H}-\mathrm{MBz}$ Proups had approximately $10 \%$ responses. Multicellular organismal process accounted for $7 \%$ of biological function in H-BPA and H-genistein girls, and $4 \%$ and $1 \%$ in H-MEHP and $\mathrm{H}-\mathrm{MBzP}$ girls, respectively. Proteins associated with reproduction were highest in MEHP girls (7\%), and apoptotic process and biologic adhesion constituted $3 \%$ of biological functions in H-genistein and 
Table continued...

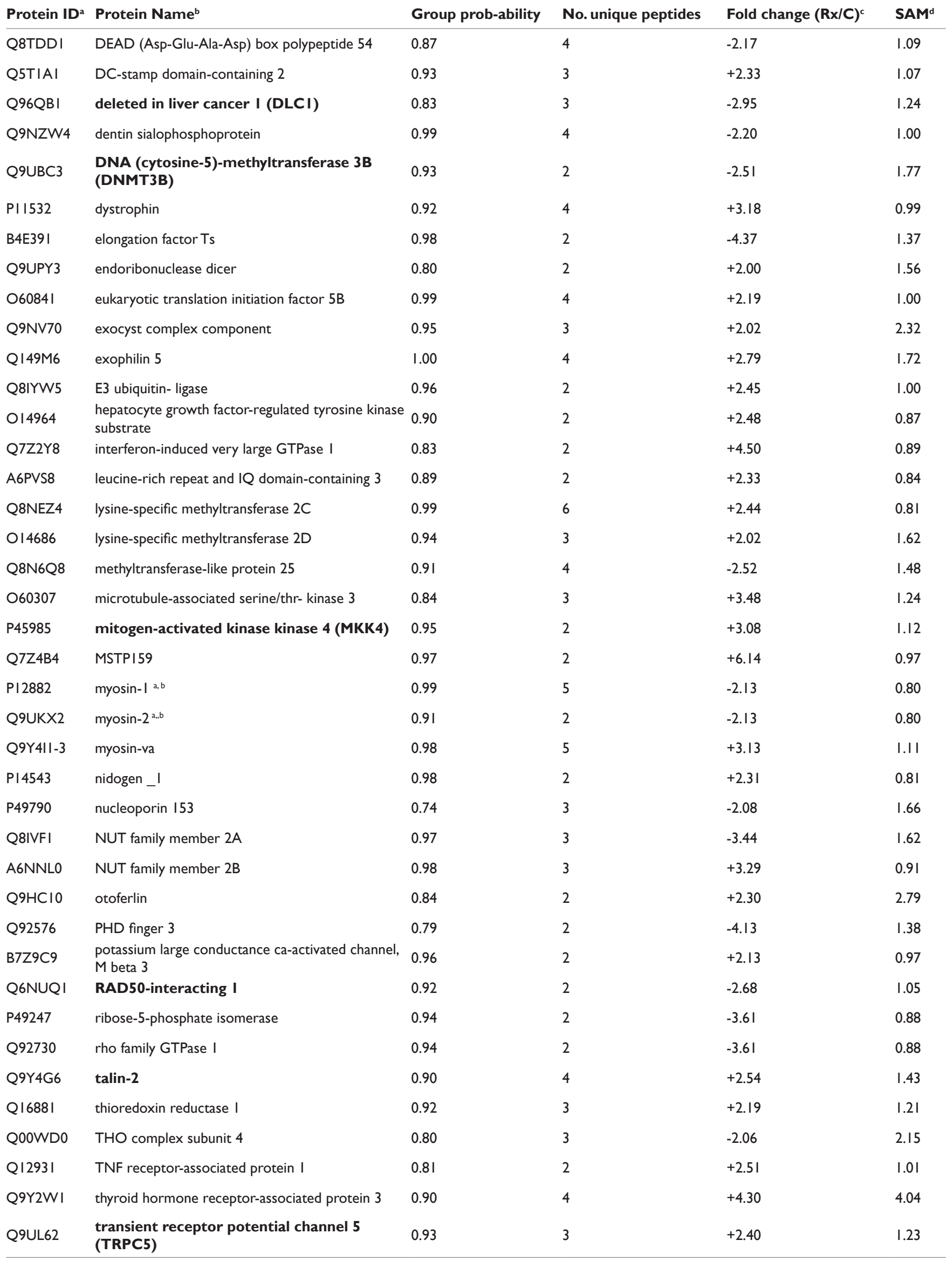


Table continued...

\begin{tabular}{|c|c|c|c|c|c|}
\hline Protein ID I $^{a}$ & Protein Name $^{b}$ & Group prob-ability & No. unique peptides & Fold change $(R x / C)^{c}$ & SAM $^{d}$ \\
\hline PI7948 & vascular endothelial growth factor receptor I & 1.00 & 4 & -2.21 & 0.87 \\
\hline Q64LD2 & WD repeat-containing 25 & 0.99 & 2 & +2.25 & 0.86 \\
\hline OI523I & zinc finger 185 & 0.92 & 2 & +2.72 & 0.98 \\
\hline
\end{tabular}

${ }^{\text {aP }}$ roteins identified using the Human Genome DB ID.

bProteins in bold are carcinogenesis-related proteins.

cPositive and negative fold change in protein expression indicate up- and down-regulation of protein expression relative to control, respectively.

dSignificance analysis of microarray (SAM); cut off $| \pm 0.8|$ calculated as described in Materials and Methods.

Table 3 Differentially Regulated Proteins Identified by TM-MS in Sera of Girls with High Urine Concentrations of Genistein.

\begin{tabular}{|c|c|c|c|c|c|}
\hline Protein ID ${ }^{\mathrm{a}}$ & Protein Name ${ }^{b}$ & Group prob-ability & No. unique peptides & Fold Change $(\mathbf{R x} / \mathrm{C})^{c}$ & SAM $^{d}$ \\
\hline Q9H0C2 & ADP/ATP translocase 4 & 0.99 & 3 & +2.02 & 1.15 \\
\hline A4D0V7 & cadherin-like and PC-esterase domain containing I & 0.95 & 2 & -2.21 & 1.22 \\
\hline Q8WW4 & chromosome 2 Open Reading Frame 47 & 0.93 & 2 & -4.56 & 0.91 \\
\hline A6NNT2 & chromosome 16 open reading frame 96 & 0.95 & 3 & -2.07 & 5.27 \\
\hline P53621 & coatomer alpha subunit & 0.99 & 5 & -2.18 & 1.10 \\
\hline O43293 & death associated kinase & 0.86 & 3 & -2.77 & 1.38 \\
\hline P52429 & diacylglycerol kinase epsilon & 0.90 & 2 & -3.25 & 1.29 \\
\hline Q9C098 & doublecortin-like kinase 3 & 0.98 & 4 & -2.66 & 1.40 \\
\hline P42892 & endothelin-converting enzyme (ECE-I) & 1.00 & 4 & -2.12 & 1.72 \\
\hline B4DUI3 & $\begin{array}{l}\text { eukaryotic translation initiation factor } 3 \text { subunit J } \\
\text { (EIF3) }\end{array}$ & 0.82 & 2 & -2.30 & 1.63 \\
\hline Q96JP0 & fem-I homolog C & 0.92 & 2 & +2.02 & 1.45 \\
\hline Q5CZC0 & fibrous sheath-interacting 2 & 0.93 & 5 & -2.17 & 0.97 \\
\hline 060318 & germinal-center associated nuclear protein & 0.88 & 2 & -2.26 & 1.09 \\
\hline B9A064 & immunoglobulin lambda-like polypeptide 5 & 0.92 & 3 & -3.48 & I.II \\
\hline Q6NSI8 & KIAAI84I & 0.98 & 3 & -2.70 & 1.47 \\
\hline Q5QGS0 & KIAA2022 & 0.91 & 2 & +2.56 & 1.13 \\
\hline Q9Y496 & kinesin-like protein & 0.82 & 2 & +2.47 & 1.20 \\
\hline Q9UMYI & nucleolar 7 & 0.82 & 2 & +2.10 & 1.02 \\
\hline Q9NQXI & PR domain zinc finger 5 (PRDM5) & 0.97 & 5 & +2.30 & 0.95 \\
\hline Q9UQ6 & regulating synaptic membrane exocytosis 2 & 0.94 & 3 & -2.82 & 0.93 \\
\hline $\mathrm{A} 8 \mathrm{KOH} 3$ & ribosomal L29 & 0.99 & 3 & -2.73 & 1.81 \\
\hline Q8IYFI & RNA polymerase II transcription factor SIII sub A2 & 0.89 & 4 & +2.28 & 1.22 \\
\hline PI0523 & s-arrestin & 0.96 & 2 & -2.38 & 3.26 \\
\hline Q6R2W3 & SCAN domain-containing 3 & 0.93 & 2 & -2.27 & 0.84 \\
\hline AIX283 & $\mathrm{SH} 3$ and $\mathrm{PX}$ domain-containing $2 \mathrm{~B}$ & 0.78 & 2 & -2.79 & 1.46 \\
\hline Q7Z5N4 & sidekick & 0.83 & 3 & -2.31 & 1.68 \\
\hline Q9P2W9 & syntaxin-18 & 0.94 & 2 & +2.31 & 1.32 \\
\hline Q8N3R3 & T-Cell activation inhibitor & 0.77 & 2 & +4.56 & 1.51 \\
\hline 075643 & U5 small nuclear ribonucleo 200 kDa helicase & 0.97 & 4 & -2.11 & 1.19 \\
\hline Q6IE27 & vitellogenin-like I & 0.97 & 4 & +2.48 & 1.73 \\
\hline Q8IWGI & WD repeat-containing protein 63 & 0.96 & 3 & -6.05 & 1.02 \\
\hline Q96DT7 & zinc finger and BTB domain-containing 10 & 0.89 & 3 & -4.31 & 0.85 \\
\hline
\end{tabular}


Table continued....

\begin{tabular}{|c|c|c|c|c|c|}
\hline Protein ID ${ }^{a}$ & Protein Name ${ }^{b}$ & Group prob-ability & No. unique peptides & Fold Change $(R x / C)^{c}$ & SAM $^{\mathrm{C}}$ \\
\hline B4DSE6 & zinc finger 485 & 0.92 & 2 & -2.76 & 0.89 \\
\hline Q8N49 & zinc finger 808 & 0.85 & 3 & -3.05 & 2.62 \\
\hline
\end{tabular}

aproteins identified using the Human Genome DB ID.

bProteins in bold are consistent with cancer prevention.

'Positive and negative fold change in protein expression indicate up- and down-regulation of protein expression relative to control, respectively.

dSignificance analysis of microarray (SAM); cut off $| \pm 0.8|$ calculated as described in Materials and Methods.

Table 4 Differentially Regulated Proteins Identified by TMT-MS in Sera of Girls with High Urine Concentrations of MEHP.

\begin{tabular}{|c|c|c|c|c|c|}
\hline Protein ID ${ }^{\mathbf{a}}$ & Protein Name ${ }^{b}$ & $\begin{array}{l}\text { Group prob- } \\
\text { ability }\end{array}$ & $\begin{array}{l}\text { No. unique } \\
\text { peptides }\end{array}$ & $\begin{array}{l}\text { Fold change } \\
(\operatorname{Rx} / \mathrm{C})^{\mathrm{c}}\end{array}$ & SAM $^{d}$ \\
\hline Q9H6R3 & acyl-CoA synthetase short-chain family member 3 & 0.91 & 2 & +2.57 & 1.65 \\
\hline Q9BXX2 & ankyrin repeat domain-containing 30B & 0.97 & 4 & +2.16 & 1.44 \\
\hline Q8N7J2 & APC membrane recruitment protein 2 & 0.98 & 3 & -2.80 & 0.84 \\
\hline A8Y988 & ATP-binding cassette (Sub-family C, member 6) & 1.00 & 3 & -2.21 & 1.40 \\
\hline Q8TDI6 & bicaudal D homolog 2 & 0.93 & 2 & -2.70 & 1.57 \\
\hline $\mathrm{P} 27815$ & cAMP-specific 3',5'-cyclic phosphodiesterase 4A & 0.95 & 5 & -3.11 & 1.28 \\
\hline PI4384 & carboxypeptidase $M$ & 0.95 & 2 & -2.09 & 1.01 \\
\hline Q86X52 & chondroitin sulfate synthase I & 0.98 & 3 & -2.17 & 1.54 \\
\hline Q9P2DI & chromodomain-helicase-DNA-binding 7 & 1.00 & 5 & -2.36 & 1.69 \\
\hline Q9HCK8 & chromodomain-helicase-DNA-binding 8 & 0.95 & 5 & -2.70 & 1.81 \\
\hline Q96NII & chromosome 7 open reading frame 26 & 0.83 & 3 & -2.41 & 1.94 \\
\hline A6PVK7 & chromosome 9 open reading frame 84 & 1.00 & 3 & -2.26 & 0.90 \\
\hline Q96PX6 & coiled-coil domain-containing 85A & 0.92 & 4 & +2.15 & $\mathrm{I} .46$ \\
\hline Q8IYT3 & coiled-coil domain containing 170 & 0.98 & 2 & +2.39 & 0.87 \\
\hline P0C0L5 & complement C4B & 1.00 & 3 & +2.58 & 0.80 \\
\hline D3DUT5 & complement component I & 1.00 & 3 & -2.02 & 1.51 \\
\hline Q9NX05 & constitutive coactivator of PPAR-gamma-like 2 & 0.81 & 2 & +3.51 & 1.27 \\
\hline Q9NXE8 & CWC25 spliceosome-associated protein homolog & 0.86 & 2 & -3.38 & 1.83 \\
\hline P35663 & cylicin- I & 0.95 & 3 & -3.44 & 1.14 \\
\hline Q14008 & cytoskeleton-associated 5 & 0.97 & 4 & -2.73 & 4.09 \\
\hline Q8N254 & DEAD/H (Asp-Glu-Ala-Asp/His) box polypeptide I & 0.85 & 3 & -2.47 & 0.85 \\
\hline Q8N919-2 & deltex 3, E3 ubiquitin ligase & 0.97 & 3 & -2.43 & 0.97 \\
\hline Q9UNI9 & dual adapter for phosphotyrosine and 3-phosphoinositides & 0.89 & 2 & -2.16 & 0.89 \\
\hline Q8WV44 & E3 ubiquitin- ligase & 0.81 & 2 & +3.06 & 0.81 \\
\hline Q96RP9-2 & elongation factor $\mathrm{G}$ & 0.89 & 3 & -7.97 & 0.89 \\
\hline Q13003 & glutamate receptor, ionotropic kainate 3 & 1.00 & 3 & -3.36 & 1.00 \\
\hline PI4866 & heterogeneous nuclear ribonucleo L & 0.78 & 2 & -2.45 & 0.78 \\
\hline P42858 & huntingtin & 0.89 & 2 & +2.43 & 0.89 \\
\hline PI7936 & insulin-like growth factor-binding protein 3 (IGFBP-3) & 1.00 & 3 & -3.44 & 1.00 \\
\hline Q14624 & inter-alpha-trypsin inhibitor heavy chain $\mathrm{H} 4$ & 0.99 & 4 & -2.17 & 0.99 \\
\hline Q9HCMI & KIAAI55I & 0.99 & 6 & -2.79 & 0.99 \\
\hline Q9C099 & leucine-rich repeat and coiled-coil domain-containing I & 0.98 & 5 & -2.19 & 0.98 \\
\hline
\end{tabular}


Table continued....

\begin{tabular}{|c|c|c|c|c|c|}
\hline Protein ID ${ }^{a}$ & Protein Name ${ }^{b}$ & $\begin{array}{l}\text { Group prob- } \\
\text { ability }\end{array}$ & $\begin{array}{l}\text { No. unique } \\
\text { peptides }\end{array}$ & $\begin{array}{l}\text { Fold change } \\
(\mathrm{Rx} / \mathrm{C})^{c}\end{array}$ & SAM $^{d}$ \\
\hline Q9NZR2 & low-density lipo receptor-related IB & 0.96 & 3 & -2.20 & 0.96 \\
\hline $\mathrm{P} 26927$ & macrophage stimulating protein I & 1.00 & 3 & -2.05 & 1.00 \\
\hline Q8NBI6 & mixed lineage kinase domain-like & 0.95 & 2 & -3.58 & 0.95 \\
\hline Q96T76-7 & MMSI9 nucleotide excision repair homolog & 0.85 & 2 & -2.51 & 0.85 \\
\hline PII055 & myosin-3 & 0.83 & 4 & -2.37 & 0.83 \\
\hline Q3T906 & $\mathrm{N}$-acetylglucosamine-I-phosphotransferase subunits alpha/beta & 0.98 & 3 & -2.41 & 0.98 \\
\hline P37198 & nuclear pore glyco p62 & 0.90 & 2 & -3.00 & 0.90 \\
\hline QI7RR3 & pancreatic lipase-related 3 & 0.98 & 2 & -3.20 & 0.98 \\
\hline 000329 & phosphatidylinositol 3-kinase delta catalytic subunit & 0.77 & 2 & -2.07 & 0.77 \\
\hline Q86UUI & pleckstrin homology-like domain family B member I & 1.00 & 4 & -2.24 & 1.31 \\
\hline Q4G0U5 & primary ciliary dyskinesia I & 0.96 & 2 & +3.59 & 2.96 \\
\hline 095206 & protocadherin-8 & 1.00 & 3 & -5.00 & 1.25 \\
\hline B7Z4Q3 & RNA-binding Luc7-like & 0.82 & 3 & -2.03 & 0.84 \\
\hline Q6PCB5 & round spermatid basic I-like & 0.98 & 3 & -2.19 & 1.24 \\
\hline B4DZM2 & SFRS2-interactin & 1.00 & 6 & -2.02 & 2.18 \\
\hline Q59HF0 & solute carrier family I 3 (sodium/sulfate symporters), member 4 & 0.93 & 2 & -3.01 & 0.81 \\
\hline B7ZLS9 & synaptonemal complex I & 1.00 & 5 & +2.26 & 1.03 \\
\hline OI506I & synemin & 1.00 & 5 & -2.32 & 2.79 \\
\hline AOAVFI & tetratricopeptide repeat 26 & 0.88 & 2 & -2.88 & 0.92 \\
\hline Q9BUB4 & tRNA-specific adenosine deaminase I & 0.97 & 3 & -3.73 & 1.04 \\
\hline Q2NL82 & TSRI, 20S rRNA accumulation, homolog & 0.92 & 2 & -2.98 & 1.60 \\
\hline Q9C0G0 & zinc finger 407 & 0.98 & 5 & -2.30 & 1.10 \\
\hline A7MD06 & zinc finger 483 & 0.91 & 2 & -2.02 & 1.86 \\
\hline Q9NUD5 & zinc finger $\mathrm{CCHC}$ domain-containing 3 & 0.97 & 2 & -2.17 & 1.06 \\
\hline Q9CX48 & zinc finger $\mathrm{CCHC}$ domain-containing 10 & 0.73 & 3 & -2.98 & 1.03 \\
\hline
\end{tabular}

aProteins identified using the Human Genome DB ID.

'Proteins in bold are carcinogenesis-related proteins.

'Positive and negative fold change in protein expression indicate up- and down-regulation of protein expression relative to control, respectively.

dSignificance analysis of microarray (SAM); cut off $| \pm 0.8|$ calculated as described in Materials and Methods.

Table 5 Differentially Regulated Proteins Identified by TMT-MS in Sera of Girls with High Urine Concentrations of MBzP

\begin{tabular}{|c|c|c|c|c|c|}
\hline Protein ID $^{a}$ & Protein name $^{b}$ & $\begin{array}{l}\text { Group prob- } \\
\text { ability }\end{array}$ & $\begin{array}{l}\text { No. unique } \\
\text { peptides }\end{array}$ & Fold change $(R x / C)^{c}$ & SAM $^{d}$ \\
\hline Q9UJX4 & anaphase-promoting complex subunit 5 & 0.87 & 2 & -2.26 & 1.26 \\
\hline Q9UBJ2 & ATP-binding cassette sub-family D member 2 & 0.86 & 2 & -3.45 & 3.18 \\
\hline Q5XSY0 & ATP synthase subunit a & 0.96 & 2 & +2.25 & 1.09 \\
\hline Q9NPII & bromodomain-containing 7 & 1.00 & 3 & +2.47 & 0.90 \\
\hline $\mathrm{O} 14578$ & citron Rho-interacting kinase & 0.99 & 5 & +2.95 & $\mathrm{I} .4 \mathrm{I}$ \\
\hline P35663 & cylicin-I & 0.99 & 4 & +2.16 & 1.02 \\
\hline Q9HCKI & DBF4-type zinc finger-containing 2 & 1.00 & 5 & -2.34 & 1.10 \\
\hline
\end{tabular}


Table continued....

\begin{tabular}{|c|c|c|c|c|c|}
\hline Protein ID ${ }^{a}$ & Protein name $^{b}$ & $\begin{array}{l}\text { Group prob- } \\
\text { ability }\end{array}$ & $\begin{array}{l}\text { No. unique } \\
\text { peptides }\end{array}$ & Fold change $(R x / C)^{c}$ & SAM $^{d}$ \\
\hline O60231 & DEAH (Asp-Glu-Ala-His) box polypeptide I6 & 0.88 & 3 & +4.94 & 1.53 \\
\hline Q99543 & DnaJ homolog subfamily $\mathrm{C}$ member 2 & 0.99 & 2 & +2.57 & 0.92 \\
\hline 060673 & DNA polymerase zeta catalytic subunit & 0.92 & 2 & -2.66 & 0.95 \\
\hline Q8WXX0 & dynein heavy chain 7 & 0.80 & 2 & +2.11 & 2.33 \\
\hline O754II & Krueppel-like factor IO (KLFI0) & 0.95 & 2 & +2.61 & 1.47 \\
\hline P08F94 & fibrocystin & 0.98 & 2 & -2.16 & 1.07 \\
\hline Q5TBA9 & furry homolog & 0.96 & 5 & +2.51 & 1.02 \\
\hline A6NFK2 & glutaredoxin domain-containing cysteine-rich 2 & 0.99 & 2 & -2.65 & 0.87 \\
\hline $\mathrm{PIOI44}$ & granzyme B & 0.81 & 3 & +3.41 & 2.18 \\
\hline B4DRD6 & histone $\mathrm{HI}$ & 1.00 & 4 & +2.28 & 1.22 \\
\hline Q9BYW2 & histone-lysine $\mathrm{N}$-methyltransferase & 0.99 & 3 & -3.36 & 1.53 \\
\hline D3DW85 & iron-responsive element binding 2 & 0.94 & 2 & +2.30 & 1.47 \\
\hline O60738 & KB07 & 0.97 & 2 & +2.58 & 1.27 \\
\hline B0YJ32 & laminin alpha-3 chain I & 1.00 & 7 & +2.73 & 0.85 \\
\hline O95447 & leber congenital amaurosis 5 -like & 0.88 & 2 & -3.05 & $\mathrm{I} .84$ \\
\hline B3KNZ9 & megakaryocyte-associated tyrosine- kinase & 0.98 & 2 & +2.37 & 1.33 \\
\hline Q6P444 & mitochondrial fission regulator 2 & 0.98 & 2 & +3.02 & 1.08 \\
\hline Q9Y3A3 & MOB family member 4 , phocein & 0.99 & 3 & -2.15 & 2.70 \\
\hline Q9UKN7 & myosin-XV & 0.88 & 3 & -2.81 & 1.07 \\
\hline 060313 & optic atrophy I & 0.75 & 2 & +2.26 & $\mathrm{I} .4 \mathrm{I}$ \\
\hline Q9BRX2 & pelota homolog & 0.75 & 2 & +2.73 & 2.16 \\
\hline Q9BVI0-2 & PHD finger protein 20 & 0.71 & 2 & +2.21 & 0.95 \\
\hline P78356 & phosphatidylinositol-5-phosphate 4-kinase type-2 beta & 0.87 & 2 & -2.80 & 1.34 \\
\hline Q9ULM0 & pleckstrin homology domain-containing family $\mathrm{H}$ member I & 0.99 & 2 & +2.16 & 1.02 \\
\hline Q13563 & polycystin-2 & 0.85 & 2 & +3.96 & 3.05 \\
\hline Q96P66 & probable G- coupled receptor I0I & 0.84 & 2 & +2.14 & 1.30 \\
\hline Q05BX6 & RABEPI & 0.91 & 3 & +2.22 & 1.81 \\
\hline A8K 322 & RAD54 homolog B (RAD54B) & 0.85 & 3 & +2.01 & 2.72 \\
\hline Q9NS23 & ras association domain-containing I & 0.72 & 2 & -3.29 & I.II \\
\hline P06400 & retinoblastoma-associated protein (RBI) & 0.95 & 2 & +2.30 & 0.90 \\
\hline P27I69 & serum paraoxonase/arylesterase I & 1.00 & 2 & +2.61 & 2.33 \\
\hline B3KWZ6 & sperm associated antigen 17 & 0.96 & 4 & +2.28 & 1.01 \\
\hline Q5VWG9 & transcription initiation factor TFIID subunit 3 & 0.80 & 2 & +2.24 & 1.29 \\
\hline A0PJ48 & TAOK2 & 0.97 & 4 & +3.05 & 0.86 \\
\hline P28289 & tropomodulin-I & 0.93 & 2 & +2.57 & 0.93 \\
\hline P04275 & von Willebrand factor & 0.97 & 5 & +2.31 & 0.97 \\
\hline
\end{tabular}


Table continued...

\begin{tabular}{|c|c|c|c|c|c|}
\hline Protein ID ${ }^{\mathrm{a}}$ & Protein name ${ }^{b}$ & $\begin{array}{l}\text { Group prob- } \\
\text { ability }\end{array}$ & $\begin{array}{l}\text { No. unique } \\
\text { peptides }\end{array}$ & Fold change $(R x / C)^{c}$ & SAM $^{d}$ \\
\hline 043345 & zinc finger 208 & 0.88 & 3 & +2.29 & 1.92 \\
\hline P49207 & 60 S ribosomal L34 & 0.95 & 2 & +2.24 & $\mid .31$ \\
\hline
\end{tabular}

aProteins identified using the Human Genome DB ID.

bProteins in bold are consistent with cancer prevention.

'Positive and negative fold change in protein expression indicate up- and down-regulation of protein expression relative to control, respectively.

¿Significance analysis of microarray (SAM); cut off $| \pm 0.8|$ calculated as described in Materials and Methods.

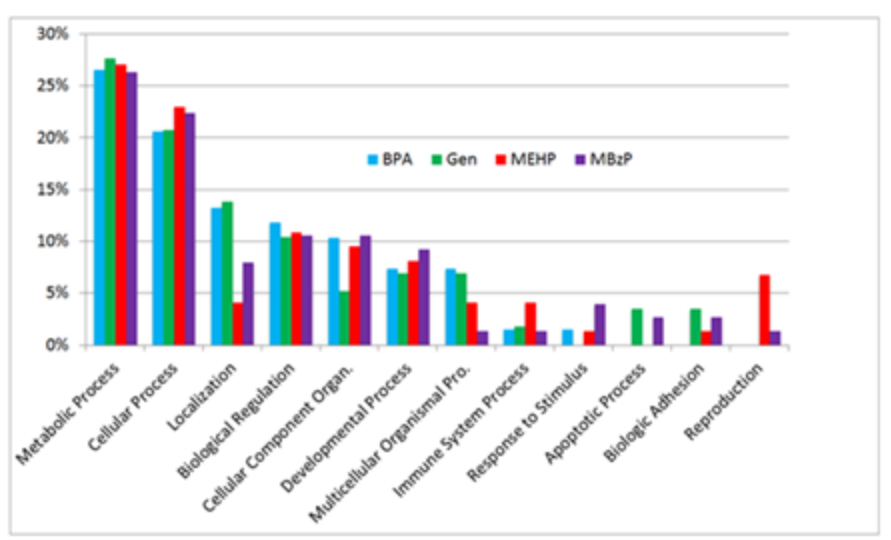

Figure I Bar graph representation of proteins classified by biological function. Analysis was carried out via PANTHER on differentially regulated proteins identified via TMT-MS from blood of prepubertal girls with high urine concentrations of BPA, genistein, MEHP and MBzP.

Of the 189 total proteins identified in the four groups of girls, only one (E3 ubiquitin-ligase) was up regulated in the blood of both H-BPA and H-MEHP girls. E3 ubiquitin-ligases have been reported to promote cancer cell proliferation and are frequently over expressed in human cancer development. ${ }^{36}$ They are also associated with chemo-resistance, poor clinical prognosis, and have been suggested as potential cancer biomarkers. On the other hand, cycilin-1, a protein reported to play a role in spermatid differentiation, ${ }^{37}$ was down regulated in H-MEHP girls and up regulated in $\mathrm{H}-\mathrm{MBz} P$ girls. The significance of cycilin-1 in girls has not yet been identified. Beyond these two proteins, we noted a large number of unique protein signatures in the blood of each group. We expected, and found, that these exposure groups yielded different biomarkers of effect. Therefore, we assessed individual protein function and canonical pathway analysis towards cancer for all four chemical exposure groups, followed this up with literature searches, and considered directional change in protein expressions.

\section{High-BPA group}

From the H-BPA group of biomarkers of effect, IPA canonical pathways of function identified 10 proteins to be associated with cancer, seven of these being up regulated: ankyrin 2, antigen Ki-67, E3 ubiquitin-ligase, talin 2, transient receptor potential channel 5 (TRPC5), mitogen-activated kinase kinase 4 (MKK4) and zinc finger 185 (Table 2). Ankyrin 2 is a cytoskeletal protein that plays a role in metastatic breast tumor cell invasion and migration. ${ }^{38}$ Antigen Ki67 is a cellular marker for proliferation and used as a biomarker for cancer. ${ }^{39}$ Furthermore, we have previously reported that exposure of rats to BPA resulted in increased Ki67 protein expression in mammary glands ${ }^{40}$ and increased chemically-induced mammary cancer in rats. ${ }^{13}$ As noted in the previous paragraph, up regulated E3 ubiquitin-ligase has been reported to play a role in carcinogenesis and proposed as a biomarker of cancer. ${ }^{36}$ Talin2 is up regulated in invasive breast carcinomas. ${ }^{41}$ The expression of TRPC5 protein is high in human breast tumors and in the circulation..$^{42}$ MKK4 is an important mediator of cellular responses to extracellular signals that include growth factors, hormones, cytokines and environmental stresses. ${ }^{43}$ The role of MKK4 in cancer development appears complex, as some studies support pro-oncogenic mechanisms, while others suggest suppressor protein action. ${ }^{44}$ The JNK and p38 pathways are implicated in tumor suppression in the presence of loss of function mutations in the MKK4 gene, ${ }^{45,46}$ while MKK4 and JNK can participate in tumor formation, suggesting a more complex role for this pathway in tumor development. ${ }^{45,47}$ While it is plausible that up regulated MKKA could be a biomarker of BPA chemical exposure, the partnering of MKK4 with other signaling proteins appears to determine the functional outcome. On the other hand, up regulation of Zinc finger 185 in H-BPA girls is not consistent with carcinogenesis. Zinc finger 185 has been reported to function as a growth inhibitory protein by associating with the actin-cytoskeleton. ${ }^{48}$ But, up regulated zinc finger 185 in girls with H-BPA does not support the concept of this protein contributing to cancer causation.

Three blood proteins found by TMT-MS to be down regulated in blood of girls with high urine concentrations of BPA are deleted in liver cancer 1 (DLC1), DNA (cytosine-5)-methyltransferase 3B (DNMT3B) and RAD50-interacting 1. DLC1 functions as a tumor suppressor in a number of common cancers, including breast, liver, prostate, lung and colorectal cancers. ${ }^{49}$ Thus, a BPA mediated decrease in the tumor suppressor DLC1 may facilitate tumor development. On the other hand, DNMT3B expression is essential for mammalian development and is required for genome wide de novo methylation. ${ }^{50}$ RAD50-interacting 1 is reported to play a role in cell cycle checkpoint control after DNA damage. ${ }^{51}$ Down regulation of RAD50-interacting 1 would potentially allow cell proliferation of DNA damage to continue unchecked. In comparing the functions of the differentially expressed proteins with the directional change in protein expressions, we suggest that nine of the 10 cancer-related proteins in the blood of girls with H-BPA could actually play a role in predisposing for cancer, ankyrin-2, antigen Ki-67, E3 ubiquitin-ligase, talin-2, MKK4, TRPC5, DLC1, DNMT3B and RAD50-interacting 1.

\section{High genistein group}

In blood of girls with high genistein concentrations in their urine, two proteins with cancer associations were down regulated: endothelin-converting enzyme (ECE-1) and eukaryotic translation initiation factor 3 subunit J (EIF-3) (Table 3). ECE-1 has been implicated in the pathogenesis of a range of disease states including breast, gynecological and urological cancers, cardiovascular disease and Alzheimer's disease. ${ }^{52}$ EIF-3 has been found elevated in human breast, cervical, esophageal, and lung cancers, suggesting a potential role in malignant transformation and cell growth control..$^{53}$ 
On the other hand, nucleolar 7 and PR domain zinc finger 5 (PRDM5) are proteins that are up regulated in H-genistein girls. Nuclear 7 and PRDM5 have been reported to regulate the cell cycle. The nucleolar 7 gene is reported to be a candidate tumor suppressor gene in cervical cancer that modulates the angiogenic phenotype.$^{54}$ PRDM5 has growth suppressive activities and is silenced in breast, ovarian, liver, lung, colon, and other cancers. ${ }^{55}$ All four proteins should be considered as biomarkers of susceptibility for genistein/soy and cancer prevention. Interestingly, from PANTHER analysis of biological functions, the H-genistein group had the highest response on apoptotic process, a finding that corresponds very well with our report of apoptosis being increased in mammary glands of rats exposed ly to genistein. ${ }^{40}$

\section{H-MEHP group}

From the blood of girls with high MEHP concentrations in the urine, only two proteins were associated with cancer, up regulated E3 ubiquitin-ligase and insulin growth factor binding protein-3 (IGFBP-3) (Table 4). As noted earlier, E3 ubiquitin-ligase which was also up regulated in H-BPA girls is expressed in human cancer. ${ }^{36}$ On the other hand, IGFBP-3 plays a role in DNA damage repair and activation of caspase-dependent apoptosis. IGFBP-3 is a potent tumor suppressor in a variety of cancers, including breast, ovarian and prostate. ${ }^{56,57}$ Down regulated IGFBP-3 suggests less potential to repair DNA damage and to suppress cancer, and consequently it would be regarded as an event that could lead to cancer development. PANTHER biological functions also showed the highest response in the category of reproduction, a finding consistent with previous reports for animal studies with the parent compound, DEHP. ${ }^{18,19,58}$ Also, canonical pathway analysis listed five genes/proteins being differentially regulated in the category of nucleic acid metabolism and small molecule biochemistry i.e., ATP-binding cassette, chromodomain-helicase-DNA-binding 8,DEAD/H (Asp-Glu-AlaAsp/His) box polypeptide 1, huntingtin and myosin-3 .

\section{H-MBzP group}

From the 47 proteins differentially regulated in the blood of girls with high urine concentrations of MBzP, three have strong cancer associations. Krueppel-like factor-10 (KLF10), RAD54B and retinoblastoma-associated protein (RB1) are all up regulated (Table 5). The KLF10 protein has been shown to inhibit the growth of cancers, and the loss of KLF10 expression in advanced pancreatic cancer is correlated with altered methylation status. ${ }^{59}$ The RAD54B gene is highly expressed in testis and spleen, which suggests active roles in meiotic and mitotic recombination. Homozygous mutations of this gene were observed in primary lymphoma and colon cancer. ${ }^{60}$ This gene is involved in homologous recombination and repair of DNA. RAD54B protein binds to double-stranded DNA and displays ATPase activity in the presence of DNA. RB1 is a negative regulator of the cell cycle and acts as a tumor suppressor. The function of phosphorylated RB1 is to prevent excessive cell growth by inhibiting cell cycle progression until a cell is ready to divide. Defects in this gene are a cause of the childhood cancer retinoblastoma, bladder cancer, and osteogenic sarcoma. ${ }^{61} \mathrm{Up}$ regulation of these three proteins in the $\mathrm{H}-\mathrm{MBz} \mathrm{P}$ group argues for tumor suppression. However, cancer prevention has not yet been demonstrated for BBP/MBzP. On the other hand, IPA canonical pathways of function identified several proteins in $\mathrm{H}-\mathrm{MBzP}$ girls that are associated with cellular assembly and organization, cellular function and maintenance: up regulated apolipo E, citron Rho-interacting kinase, granzyme B, megakaryocyteassociated tyrosine-kinase, optic atrophy $1, \mathrm{RB} 1$, serum paraoxonase/ arylesterase1, TAOK2 and von Willebrand factor, and down regulated fibrocystin and Ras association domain-containing 1. As seen here, proteomic data should find use in identifying biomarkers of susceptibility of other diseases.

\section{Validation of differentially regulated proteins by western blot analysis}

The use of specific antibodies provides an independent method of protein identification and quantification from that of mass spectrometry. For this, we used Western blot analysis of mammary glands of rats exposed lactationally to BPA or genistein to investigate changes in the expression levels of DLC-1, ECE-1 and EIF3. These proteins were selected based on their potential impact to predispose for or prevent cancer, and the availability of commercially prepared antibodies. Consistent with the results obtained with TMT-MS, Western blot analysis showed that in mammary glands of 50day old female rats whose dams were gavaged with BPA from days 2-20 postpartum, DLC-1 was down regulated (50\% decrease) (Figure 2). Also, from mammary glands of 50day old female rats lactationally exposed to genistein during the period, ECE-1 and EIF3 were down regulated ( $60 \%$ and $51 \%$, respectively).

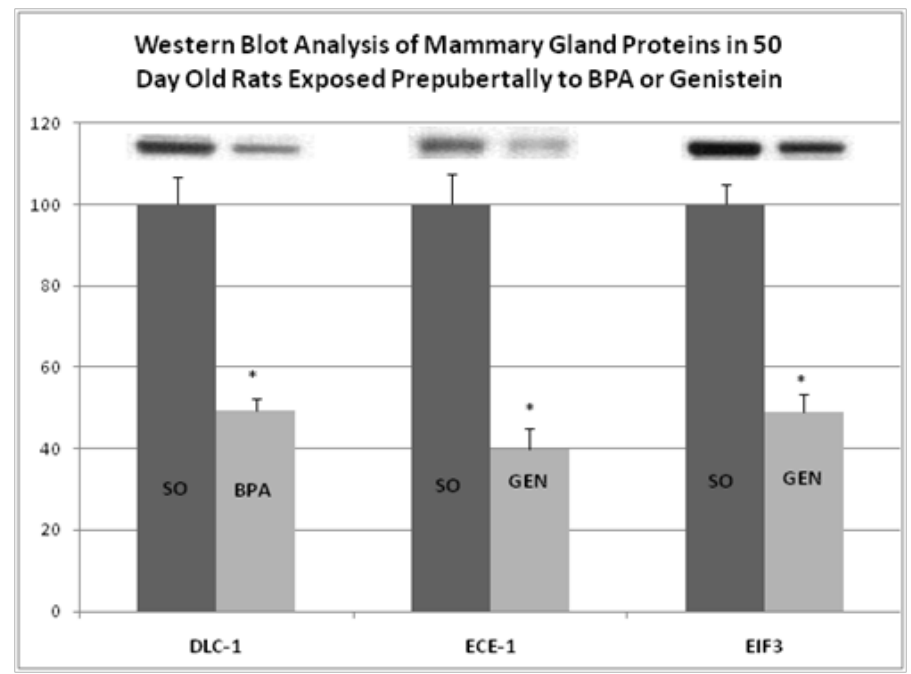

Figure 2 Western blot analysis of DLC-I, ECE-I and EIF3 in the mammary glands of PND50 rats exposed prepubertally via lactation to control (SO), BPA or genistein (GEN). Panel A. Quantification is reported as the percent of control with densitometry values for controls set to 100.Values represent mean density $\pm S E M$ as a percent of the control group ( $n=6$ per group).Asterisk $(*)$ indicates statistically significant difference in detected protein abundance compared to control $(\mathrm{p}<0.00 \mathrm{I})$. Inserts are representative immuno-blots of $40 \mu \mathrm{g}$ of serum protein from the SO and BPA- or GEN-treated groups.

We are aware of limitations of this report, including sample size and unknown origin of the proteins assessed in the blood i.e., breast, liver, kidney, blood cells, etc. Likewise for proteins that have multiple target organ/tissue origins, we do not know the individual environmental (endogenous or exogenous) regulations. One surprising observation is the lack of common protein biomarkers in rat sera ${ }^{32}$ with human blood from the same chemical exposure groups. One difference in the methods for rat and human blood enrichment is the use of rat vs. human antibodies for protein enrichment. Other differences may be due to species metabolism, regulation, or exposures (controlled onechemical exposure in rats versus multiple chemicals in humans), and/or a combined number of regulating caveats between the two species. On the other hand, we demonstrate in this report that the TMT-MS technology is reliable as evidenced by cross-species and tissue validations of three proteins from the blood of the girls and the 
mammary glands of rats exposed to BPA and genistein using Western blot analysis. This is consistent with our work on biomarkers from blood of rats exposed to BPA and genistein where we demonstrated by Western blots from blood sera similar outcome as recorded from TMTMS sera expression. ${ }^{32}$ Also, we have recently reported that exposure of rats to BPA resulted in up regulated Ki67 protein expression in mammary glands, ${ }^{40}$ in effect validating another protein shown by TMT-MS to be up regulated in the H-BPA girls.

\section{Summary}

Via the use of TMT-MS, we demonstrate unique protein signatures that can serve as biomarkers of effect from the blood of girls in the top quintiles for urine concentration of the following environmental chemicals, BPA, MEHP, MBzP and genistein. Using bioinformatics and focusing on cancer as a disease, we also identified cancer biomarkers of susceptibility for BPA and genistein exposures. The differentially regulated cancer associated proteins in $\mathrm{H}-\mathrm{BPA}$ and $\mathrm{H}$-genistein girls are especially convincing in light of divergent functions and the literature demonstrating that BPA and genistein exposures are associated with mammary cancer causation and prevention, respectively. ${ }^{11-13,31,32,62-64}$ Functional identification of proteins from blood of girls with urine high concentrations of MEHP and MBzP suggests that DEHP/ MEHP may contribute to carcinogenesis, while $\mathrm{BBP} / \mathrm{MBzP}$ may suppress cancer development. For the latter two sets of chemicals, the potential for carcinogenesis needs to be determined. Altogether, this data demonstrates the potential of proteomic technology to not only provide biomarkers of effect from aminimally invasive source of biological material, blood, but to identify protein molecules that are intimately involved in the pathobiology of cancer. Studies with a larger cohort and long term observational studies are recommended. It is hoped that identifying early functional biomarkers of cancer will lead to intervention at the preclinical stage where susceptibility may be addressed through limiting or maximizing further exposure, as well as reversing or promoting the process, depending on whether cancer promotion or protection is afforded by the exposure.

\section{Acknowledgements}

This research was supported by Genes, Environment and Health Initiative grant 1U01ES016003, the Breast Cancer and the Environment Research Program grants U01ES/CA019482, U01ES012771, U01ES019453 and U01ES019457 from the National Institute of Environmental Health Sciences (NIEHS) and the National Cancer Institute (NCI), the UAB Comprehensive Cancer Center grant NCI 5P30CA013148, P30ES006096 from NIEHS; and UL1RR026314 from the National Center for Research Resources (NCRR).The processing and analysis of the serum samples via mass spectrometry were carried out by Drs. James Mobley and Kyoko Kojima from UAB's Department of Surgery, Division of Urology and Comprehensive Cancer Center. The contents of this manuscript are solely the responsibility of the authors and do not necessarily represent the official views of the NIEHS, NCI or NIH.

\section{Conflict of interest}

The author declares no conflict of interest.

\section{References}

1. Rasier G, Toppari J, Parent AS, et al. Female sexual maturation and reproduction after prepubertal exposure to estrogens and endocrine disrupting chemicals: A review of rodent and human data. Mol Cell Endocrinol. 2006;254-255:187-201.
2. Vandenberg LN, Hauser R, Marcus $M$, et al. Human exposure to bisphenol A (BPA). Reprod Toxicol. 2007;24(2):139-177.

3. Calafat AM, Ye X, Wong LY, et al. Exposure of the U.S. population to bisphenol A and 4-tertiary-octylphenol:2003-2004. Environ Health Perspect. 2008;116(1):39-44.

4. Trasande L, Sathyanarayana S, Messito M, et al. Phthalates and the diets of US children and adolescents. Environ Res. 2013;126:84-90.

5. Melzer D, Harries L, Cipelli R, et al. Bisphenol A exposure is associated with in vivo estrogenic gene expression in adults. Environ Health Perspect. 2011;119(12):1788-1793.

6. Li DK, Miao M, Zhou Z, et al. Urine bisphenol-A level in relation to obesity and overweight in school-age children. PLoS One. 2013;8(6):e65399.

7. Shankar A, Teppala S. Relationship between urinary bisphenol A levels and diabetes mellitus. J Clin Endocrinol Metab. 2011;96(12):3822-3826.

8. Pupo M, Pisano A, Lappano R, et al. Bisphenol A induces gene expression changes and proliferative effects through GPER in breast cancer cells and cancer-associated fibroblasts. Environ Health Perspect. 2012;120(8):1177-1182.

9. Bouskine A, Nebout M, Brucker-Davis F, et al. Low doses of bisphenol A promote human seminoma cell proliferation by activating PKA and PKG via a membrane G-protein-coupled estrogen receptor. Environ Health Perspect. 2009;117(7):1053-1058.

10. Tarapore P, Ying J, Ouyang B, et al. Exposure to Bisphenol A Correlates with Early-Onset Prostate Cancer and Promotes Centrosome Amplification and Anchorage-Independent Growth In Vitro. PLoS One. 2014;9(3):e90332.

11. Durando M, Kass L, Piva J, et al. Prenatal bisphenol A exposure induces preneoplastic lesions in the mammary gland in wistar rats. Environ Health Perspect. 2007;115(1):80-86.

12. Murray TJ, Maffini MV, Ucci AA, et al. Induction of mammary gland ductal hyperplasias and carcinoma in situ following fetal bisphenol A exposure. Reprod Toxicol. 2007;23(3):383-390.

13. Jenkins S, Raghuraman N, Eltoum I, et al. Oral exposure to Bisphenol A increases dimethylbenzanthracene-induced mammary cancer in rats. Environ Health Perspect. 2009;117(6):910-915.

14. Kavlock R, Boekelheide K, Chapin R, et al. NTP Center for the evaluation of risks to human reproduction: phthalates expert panel repor on the reproductive and developmental toxicity of di(2-ethyl)phthalate. Repro Toxicology. 2002;16:529-553.

15. Ministry of Agriculture, Fisheries and Food. Survey of plasticiser levels in food contact materials and in foods, food surveillance paper. No. 21 . London: Her Majesty's Stationery Office; 1987.

16. Ministry of Agriculture, Fisheries and Food. Plasticisers: continuing surveillance, food surveillance paper No. 30. London: Her Majesty's Stationery Office; 1990.

17. NTP-CERHR Expert Panel Report on butyl benzyl phathalate. NTPCERHR-BBP-00. 2000.

18. Grande SW, Andrade AJ, Talsness CE, et al. A dose-response study following in utero and lactational exposure to di-(2-ethylhexyl) phthalate (DEHP):Reproductive effects on adult female offspring rats. Toxicology. 2007;229(1-2):114-122.

19. Davis BJ, Maronpot RR, Heindel JJ. Di-(2-ethylhexyl) phthalte suppresses estradiol and ovulation in cycling rats. Toxicol Appl Pharmacol. 1994;128(2):216-223.

20. Harris CA, Henttu P, Parker MG, et al. The estrogenic activity of phthalate esters in vitro. Environ Health Perspect. 1997;105(8):802-811. 
21. Jobling S, Reynolds $\mathrm{T}$, White $\mathrm{R}$, et al. A variety of environmentally persistent chemicals, including some phthalate plasticizers, are weakly estrogenic. Envrion Health Perspect. 1995;103(6):582-587.

22. Kluwe W, McConnell E, Huff J, et al. Carcinogenicity testing of pthalate esters and related compounds by the National Toxicology Program and the National Cancer Institute. Environ Health Perspect. 1982;45:129133 .

23. Reddy JK, Lalwai ND. Carcinogenesis by hepatic peroxisome proliferators: Evaluation of the risk of hypolipidemic drugs and industrial plasticizers to humans. Crit Rev Toxicol. 1983;12(1):1-58.

24. Diwan BA, Ward JM, Rice JM, et al. Tumor promoting effects of di(2ethylhexyl) phthalate in JB6 mouse epidermal cells and mouse skin. Carcinogenesis. 1985;6(3):343-347.

25. Adlercreutz H, Honjo H, Higashi A, et al. Urinary excretion of lignins and isoflavonoid phytoestrogens in Japanese men and women consuming a traditional diet. Am J Clin Nutr. 1991;54(6):1093-1100.

26. Lee HP, Gourley L, Duffy SW, et al. Dietary effects on breast cancer risk in Singapore. Lancet. 1991;337(8751):1197-1200.

27. Ziegler RG, Hoover RN, Hildeshein RN, et al. Migration patterns and breast cancer risk in Asian-American women. J Natl Cancer Inst. 1993;85(22):1819-1827.

28. Shu XO, Jin F, Dai Q, et al. Soyfood intake during adolescence and subsequent risk of breast cancer among Chinese women. Cancer Epidemiol Biomarkers Prev. 2001;10(5):483-488.

29. Lamartiniere CA, Murrill WB, Manzolillo PA, et al. Genistein alters the ontogeny of mammary gland development and protects agains mammary cancer in rats. Proc Soc Exp Biol Med. 1998;217(3):358-364.

30. Wolff MS, Teitelbaum SL, Pinney SM, et al. Investigation of relationships between urinary biomarkers of phytoestrogens, phthalates, and phenols and pubertal stages in girls. Environ Health Perspect. 2010;118(7):10391046.

31. Jenkins S, Betancourt AM, Wang J, et al. Endocrine-active chemicals in mammary cancer causation and prevention. J Steroid Biochem Mol Biol. 2012;129(3-5):191-200

32. Betancourt A, Mobley JA, Wang J, et al. Alterations in the rat serum proteome induced by prepubertal exposure to Bisphenol A and genistein. J Proteome Res. 2014;13(3):1502-1514.

33. Biro FM, Galvez MP, Greenspan LC, et al. Pubertal assessment method and baseline characteristics in a mixed longitudinal study of girls. Pediatrics. 2010;126(3):e583-e590.

34. Golub TR, Slonim DK, Tamayo P, et al. Molecular classification of cancer: class discovery and class prediction by gene expression monitoring. Science. 1999;286(5439):531-537.

35. Kachigan S. Multivariate statistical analysis: a conceptual introduction. 2nd ed. New York: Radius Press; 1991.

36. Sun Y. E3 ubiquitin ligases as cancer targets and biomarkers. Neoplasia. 2006;8(8):645-654.

37. He Y, Liu Z, Qiao C, et al. Expression and significance of Wnt signaling components and their target genes in breast carcinoma. Mol Med Rep. 2014:9(1):137-143

38. Lilly YWB, Zhu H, Shao L, et al. Ankyrin-tiam1 interaction promotes Rac1 signaling and metastatic breast tumor Cell invasion and migration. J Cell Biol. 2000;150(1):177-191.

39. Scholzen T, Gerdes J. The Ki-67 protein: from the known and the unknown. J Cell Physiol. 2000;182(3):311-322.

40. Wang J, Jenkins S, Lamartiniere CA. Cell proliferation and apoptosis in rat mammary glands following combinational exposure to Bisphenol A and genistein. BMC Cancer. 2014;14:379.
41. Haakensen VD, Bjoro T, Luders T, et al. Serum estradiol levels associated with specific gene expression patterns in normal breast tissue and in breast carcinomas. BMC Cancer. 2011;11:332.

42. Ma X, Chen Z, Dong H, et al. Essential role for TrpC5-containing extracellular vesicles in breast cancer with chemotherapeutic resistance. Proc Natl Acad Sci U S A. 2014;111(17):6389-6394.

43. Chang L, Karin M. Mammalian MAP kinase signaling cascades. Nature 2001;410(6824):37-40

44. Whitmarsh AJ, Davis RJ. Role of mitogen-activated protein kinase kinase 4 in cancer. Oncogene. 2007;26(22):3172-3184.

45. Kennedy NJ, Davis RJ. Role of JNK in tumor development. Cell Cycle 2003;2(3):199-201.

46. Bulavin DV, Fornace Jr AJ. p38 MAP kinase's emerging role as a tumor suppressor. Adv Cancer Res. 2004;92:95-118.

47. Wang L, Pan Y, Dai JL. Evidence of MKK4 pro-oncogenic activity in breast and pancreatic tumors. Oncogene. 2004;23(35):5978-5985.

48. Zhang JS, Gong A, Young CY. ZNF185, an actin-cytoskeletonassociated growth inhibitory LIM protein in prostate cancer. Oncogene. 2007;26(1):111-122

49. Lahoz A, Hall A. DLC1: a significant GAP in the cancer genome. Genes Dev. 2008;22(13):1724-1730.

50. Okano M, Bell DW, Haber DA, et al. DNA methyltransferases Dnmt3a and Dnmt3b are essential for de novo methylation and mammalian development. Cell. 1999;99(3):247-257.

51. Xiao J, Liu CC, Chen PL, et al. RINT-1, a novel Rad50-interacting protein, participates in radiation-induced $\mathrm{G} 2 / \mathrm{M}$ checkpoint control. $J$ Biol Chem. 2001;276(9):6105-6111.

52. Smollich M, Wulfing P. Targeting the endothelin system: nove therapeutic options in gynecological, urological and breast cancers. Expert Rev Anticancer Ther. 2008;8(9):1481-1493.

53. Dong Z, Liu LH, Han B, et al. Role of eIF3 p170 in controlling synthesis of ribonucleotide reductase M2 and cell growth. Oncogene. 2004;23(21):3790-3801

54. Hasina R, Pontier AL, Fekete MJ, et al. NOL7 is a nucleolar candidate tumor suppressor gene in cervical cancer that modulates the angiogenic phenotype. Oncogene. 2006;25(4):588-598.

55. Deng Q, Huang S. PRDM5 is silenced in human cancers and has growth suppressive activities. Oncogene. 2004;23(28):4903-4910.

56. Colón I, Caro D, Bourdony CJ, et al. Identification of phthalate esters in the serum of young Puerto Rican girls with premature breast development. Environ Health Perspect. 2000;108(9):895-900.

57. Torng PL, Lee YC, Huang CY, et al. Insulin-like growth factor binding protein-3 (IGFBP-3) acts as an invasion-metastasis suppressor in ovarian endometrioid carcinoma. Oncogene. 2008;27(15):2137-2147.

58. Lin MZ, Marzec KA, Martin JL, et al. The role of insulin-like growth factor binding protein-3 in the breast cancer cell response to DNAdamaging agents. Oncogene. 2014;33(1):85-96.

59. Chang VH, Chu PY, Peng SL, et al. Krüppel-like factor 10 expression as a prognostic indicator for pancreatic adenocarcinoma. Am J Pathol. 2012;181(2):423-430.

60. Hiramoto T, Nakanishi T, Sumiyoshi T, et al. Mutations of a nove human RAD54 homologue, RAD54B, in primary cancer. Oncogene. $1999 ; 18(22): 3422-3426$

61. Corson TW, Gallie BL. One hit, two hits, three hits, more? Genomic changes in the development of retinoblastoma. Genes Chromosomes Cancer. 2007;46(7):617-634 
62. Hilakivi-Clarke L, Onojafe I, Raygad M, et al. Prepubertal exposure to zearalenone or genistein reduces mammary tumorigenesis. Br J Cancer. 1999;80(11):1682 - 1688.

63. Lamartiniere CA, Zhao YX, Fritz WA. Genistein: mammary cancer chemoprevention, in vivo mechanisms of action, potential for toxicity, and bioavailability in rats. $J$ Women's Cancer. 2000;2:11-19.
64. Badger TM, Ronis MJ, Hakkak R, et al. The health consequences of early soy consumption. J Nutr. 2002;132(3):559S-565S. 